\title{
Activation of Jordanian Bentonite by Hydrochloric Acid and Its Potential for Olive Mill Wastewater Enhanced Treatment
}

\author{
Khansaa Al-Essa $(\mathbb{D}$ \\ Department of Chemistry, Faculty of Science, Jerash University, Jerash 26150, Jordan \\ Correspondence should be addressed to Khansaa Al-Essa; khansaa.essa@gmail.com
}

Received 7 December 2017; Revised 19 January 2018; Accepted 4 February 2018; Published 12 March 2018

Academic Editor: Wenshan Guo

Copyright (C) 2018 Khansaa Al-Essa. This is an open access article distributed under the Creative Commons Attribution License, which permits unrestricted use, distribution, and reproduction in any medium, provided the original work is properly cited.

Jordanian bentonite was activated by hydrochloric acid at room temperature. FTIR, XRD, TGA, and BET surface area analyses of the samples were carried out to examine the structure of bentonite before and after acid activation. It is found that the octahedral cations were removed, which altered the chemical composition of the bentonite. Difference of surface area was noticed ( 66.2 to $287.8 \mathrm{~m}^{2} \mathrm{~g}^{-1}$ ), which was caused by structural changes in the bentonite. We aimed to investigate the effectiveness of activated bentonite in OMWW treatment. Batch and column techniques were applied. Crude and treated OMWW samples were characterized; physiochemical parameters, total phenolic compounds, and heavy metal ions concentrations were measured. Several parameters that affected the adsorption capacity were studied: the $\mathrm{pH}$ value of the solution, temperature, and the adsorbent dose. It was found that the maximum removal of total phenolic compounds and heavy metal ions ( $\mathrm{Zn}, \mathrm{Fe}$, and $\mathrm{Mn}$ ) was at $\mathrm{pH}$. Adsorption capacity of phenolic compounds was enhanced with an increase in the temperature of the solution and also with the adsorbent dose. The optimum adsorbent concentration needed for the maximum removal of total phenolic compounds is $1 \mathrm{~g}$ of activated bentonite/0.01 L of OMWW. The percentage removal exceeded $99 \%$ for $\mathrm{Zn}, \mathrm{Fe}$, and $\mathrm{Mn}$ ions, while it reached 65.2 and 61.5 for $\mathrm{K}^{+}$ and $\mathrm{Na}^{+}$ions, respectively. Finally, the percentage removal of pollutants was increased by using activated bentonite. This study will provide valuable insight into the effect of activated bentonite towards the treatment and recyclability of OMWW, which is essential for the local olive mill industry.

\section{Introduction}

The production of olive oil has been a well-known and established practice in the Mediterranean region for hundreds of years. The production of olive oil generates three products: olive oil $(20 \%)$, wet solid waste $(30 \%)$ called "crude olive cake," and an aqueous waste called "olive mill wastewater, OMWW" (50\%) [1]. These wastes cause an important environmental problem, when they are generated in large quantities over short periods of time. OMWW has a high amount of hazardous pollutants which are highly toxic/phytotoxicityassociated compounds, and they resist biological degradation [2]. OMWW contains an appreciable content of phenolic compounds, consisting of monocyclic aromatic molecules, such as tyrosol, catechol, and caffeic acid [3]. Moreover, it also contains a considerable content of inorganic compounds, such as heavy metals, phosphorus, potassium, and nitrogen [4]. Its uncontrolled disposal into water sources leads to severe problems for the whole ecosystem and especially for natural water life. If it is disposed directly onto soil, it damages the properties of the soil, and it can be toxic for microorganisms, algae, plants, and insects [5]. For example, a high content of phosphorus content accelerates the growth of algae resulting in eutrophication [6]. Furthermore, a high concentration of potassium affects the cation exchange capacity of the soil, leading to a change of environmental conditions for soil microorganisms and this situation results in changes in the fertility of the soil [7]. In addition, increasing the concentration of nitrogen generally has a negative effect on microbial biomass in soil, such as direct inhibition, resulting in soil imbalance. It also affects some plants and often they die [8].

Different approaches have been developed to minimize the risks resulting from the use of OMWW including chemical oxidation [9]: adsorption on active carbon [10], ion exchange [11], membrane technologies and reverse osmosis [12], chemical reduction [13], and electrochemical methods [14]. However, most current technologies are often found to 
be expensive and time consuming, as well as sometimes being ineffective. Adsorption, on the other hand, has a great potential in the area of wastewater treatment, due to its low maintenance costs, high efficiency, and ease of operation [15]. Some researchers used synthesized and commercial adsorbents for the removal of phenolic compounds from OMWW; aminemodified mesoporous silica and activated carbon adsorbents were used for actual OMWW [16]. Macroreticular aromatic polymer (FPX66) and the macroporous polystyrene crosslinked with divinylbenzene (MN202) were used to adsorb phenol and hydroxytyrosol and other phenolic compounds [17]. In addition, green process based on resins adsorption/ion exchange (strong-base anionic Amberlyst A26 ${ }^{\circledR}$, weak-base anionic Dowex $66^{\circledR}$, and nonionic macroreticular Amberlite XAD4 ${ }^{\circledR}$ ) was also studied [18]. Moreover, batch and continuous flow adsorption of phenolic compounds from OMWW were applied using nonionic and ion exchange resins [19].

Currently, in many Mediterranean countries, especially Jordan, olive mills are usually small-scale factories, owned by low educated farmers, who cannot afford the cost of suitable wastewater treatment, unless they are provided with a low level of operating technology. Furthermore, an environmentally safe, cost-effective solution to OMWW treatment has yet to be found. Hence, this article provides a simple procedure as well as a regenerated process that can take place at the location where the water is being produced, hence no transportation costs. In addition, there is less sludge generation.

Jordanian bentonite has important physical and chemical properties, making this bentonite of special interest for industrialists, environmentalists, and engineers. It is a green nontoxic and low-cost adsorbent with local availability. In addition, it has the capability to undergo modification, in order to enhance its adsorptive properties, since the ideal adsorbent should consist of particles with a large surface area, high cation exchange capacity (CEC), chemical and mechanical stability, small diffusion resistance, and high reactivity and affinity for the pollutant [20]. One modification method is acid treatment. Acid activation of clay has been studied by many researchers $[21,22]$ and the process depends considerably on the nature and concentration of the acid and treatment time and temperature [23]. In general, the acid activation of clay minerals causes an increase in the specific surface area and number of active sites of the adsorbents [24].

The purposes of this present work are activation of Jordanian bentonite with hydrochloric acid and characterizing its physical and chemical properties. Special emphasis has been put on the OMWW, physicochemical characterization and treatment, and studying the ability of both raw and acid activated bentonite to remove phenolic compounds, $\mathrm{Zn}(\mathrm{II}), \mathrm{Fe}(\mathrm{II})$, and $\mathrm{Mn}$ (II) ions, from OMWW under various experimental conditions.

\section{Materials and Methods}

2.1. Purification of Bentonite. The natural Jordanian bentonite used in this study was collected from the airport region ( $\mathrm{Al}$ Azraq). The sample was crushed to particle size $>250 \mu \mathrm{m}$ using a ball mill instrument (clay fractions were obtained by wet sedimentation). The sample was purified in a laboratory, in order to remove quartz, carbonates, calcites, and iron hydroxide. It was dispersed in distilled water at $22^{\circ} \mathrm{C}$ and the clay fraction was recovered by centrifugation. This process was repeated four times for each sample, in order to guarantee obtaining samples in a pure form. The samples were dried in an oven at $60^{\circ} \mathrm{C}$, then ground and sieved using a $63 \mu \mathrm{m}$ mesh, and stored in tightly closed plastic bottles for use in the experiments.

2.2. Activation of Bentonite by Hydrochloric Acid. The hydrochloric acid ( $\mathrm{HCl})\left(98 \%, d=1.98 \mathrm{~g} / \mathrm{cm}^{3}\right)$ and other chemicals used are of analytical grade.

The purified bentonite was prepared for acid activation: $15 \mathrm{~g} \pm 0.01 \mathrm{~g}$ of the purified sample was weighed into a flask and $200 \mathrm{~mL}$ of $1.0 \mathrm{M} \mathrm{HCl}$ was added. The resulting suspension was stirred at room temperature for $24 \mathrm{hrs}$. At the end of the mixing duration, the resulting slurry was poured into a Buchner funnel, in order to separate the acid and bentonite. The residual bentonite was washed with deionized water several times, until it was released from $\mathrm{Cl}^{-1}$ ions against $5 \%$ $\mathrm{AgNO}_{3}$ solution. After drying the sample at $100^{\circ} \mathrm{C}$ for two hours, it was calcined in the oven at $450^{\circ} \mathrm{C}$ for four hours and the activated sample was cooled in a desiccator, then regrinded to reach $63 \mu \mathrm{m}$ particles size, and stored in tightly closed plastic bottles to be used in adsorption studies.

2.3. Collection, Preservation, and Pretreatment of OMWW Samples. OMWW was obtained from a centrifuge processing plant located at Jerash city. Samples were kept refrigerated at $-2^{\circ} \mathrm{C}$ in tightly closed plastic containers and used when required. As a pretreatment, aliquots of $1 \mathrm{~L}$ of OMWW were centrifuged at 10,000 rpm for 30 minutes and double simple filtration was undertaken, in order to obtain a clear and dark (brownish) solution.

2.4. Characterization of the OMWW. Fresh OMWW was characterized before and after pretreatment. $\mathrm{pH}$, electrical conductivity (EC), dissolved oxygen (DO), oxidation reduction potential (ORP), total dissolved solids (TDS), and salt were measured using a Crison PL-700AL meter. Chemical oxygen demand (COD), alkalinity, total nitrate, total phosphate, and total chlorine concentrations were determined using a COD and multiparameter bench meter, PN HI8309902.

The total phenolic compounds were evaluated by spectrophotometry using the Folin-Ciocalteu method. Briefly, a $2.5 \mathrm{~mL}$ portion of Folin-Ciocalteu reagent $0.2 \mathrm{~N}$ was mixed with $0.5 \mathrm{~mL}$ of the sample. The reaction was kept in the dark for five minutes. Then, $2 \mathrm{~mL}$ of a sodium carbonate solution $(75 \mathrm{~g} / \mathrm{L})$ was added to the mixture and the reaction was kept in the dark for one hour. The absorbance was measured at $765 \mathrm{~nm}$ in AAS. Contents of the total phenolic compounds in OMWW were expressed as gallic acid equivalents in grams per litre (g GAE/L residue) [25]. $\mathrm{K}^{+}$and $\mathrm{Na}^{+}$concentrations were determined using a flame photometer (Corning 400).

For the heavy metal ions determination tests, $\mathrm{Zn}, \mathrm{Fe}$, and $\mathrm{Mn}$, a standard solution of each metal ion concentration was prepared in $\mathrm{NaClO}_{4}$ at $\mathrm{pH}=6$. The $\mathrm{pH}$ of these solutions 
was adjusted using $0.1 \mathrm{M} \mathrm{HCl}$ and $0.1 \mathrm{M} \mathrm{NaOH}$, in order to achieve the desired values. Concentrations of the metal ions were determined using a Varian Spectra AA-250 pulse atomic adsorption spectrometer (AAS).

2.5. Adsorbent Characterization. The activated bentonite was characterized by FTIR spectroscopy (Thermo Nicolet NEXUS 670 Spectrophotometer), XRD (Philips X'Pert Pro), and TGA (NETZCH STA 409 PG/PC Thermal Analyzer). BET surface area analysis was determined using Gemini VII from micromeritics. The $\mathrm{pH}$ point of zero charge (PZC) of activated bentonite was carried out using a Zeta Meter 3.0 (Zeta Meter Inc.). Concentrations of total phenolic compounds were determined using a UV-VIS Spectrophotometer (Varian Cary 100).

2.6. Adsorption Methodology. The adsorption experiments were carried out by a batch technique. Effects of solution temperature and mass of acid activated bentonite on the percentage removal of total phenolic compounds were studied. Moreover, the activated bentonite was tested for the adsorption of heavy metal ions from OMWW using a column technique. Adsorption processes were carried out in a $560 \mathrm{~mm}$ long glass column with $12 \mathrm{~mm}$ inner diameter. The column was packed with $1.00 \mathrm{~g} \pm 0.0001 \mathrm{~g}$ of adsorbent. $100 \mathrm{~mL}$ of OMWW was passed through the column. The effluent was collected in 10 separate samples; each has a volume of $10 \mathrm{~mL}$. Finally, all analytical experiments were applied at least in duplicate and the mean values are presented in Figures 4-9.

Concentration of metal retained in the adsorbent phase $\left(q, \mathrm{mg} \mathrm{g}^{-1}\right)$ was calculated by the following equation:

$$
q=\frac{\left(C_{i}-C_{e}\right)}{M} * V
$$

where $q$ is the adsorbent phase concentration after equilibrium $(\mathrm{mg} / \mathrm{g}), C_{i}$ and $C_{e}$ are the initial and final equilibrium concentrations $(\mathrm{mg} / \mathrm{L})$ of metal ion in solution, $V$ is the solution volume (L), and $M$ is the adsorbent mass ( $\mathrm{g}$ ). Mass percent of the removal metal ion was calculated using the following equation:

$$
\% \text { Removal }=\frac{\left(C_{i}-C_{e}\right)}{C_{i}} * 100 .
$$

\section{Results and Discussion}

\subsection{Characterization of Adsorbent}

3.1.1. FTIR Spectrum Analysis. The FTIR analyses of the raw and activated bentonite were taken in the range of $400-4000 \mathrm{~cm}^{-1}$. The FTIR spectra of both are shown in Figure 1. It can be seen that the FTIR spectra are very sensitive to the modification of bentonite structure upon acid treatment.

The spectrum of the raw bentonite exhibits absorption bands at 3450 and $1650 \mathrm{~cm}^{-1}$ assigned to the stretching and bending vibrations of the $\mathrm{OH}$ groups for the water molecule of hydration, which adsorbed on the bentonite surface, and

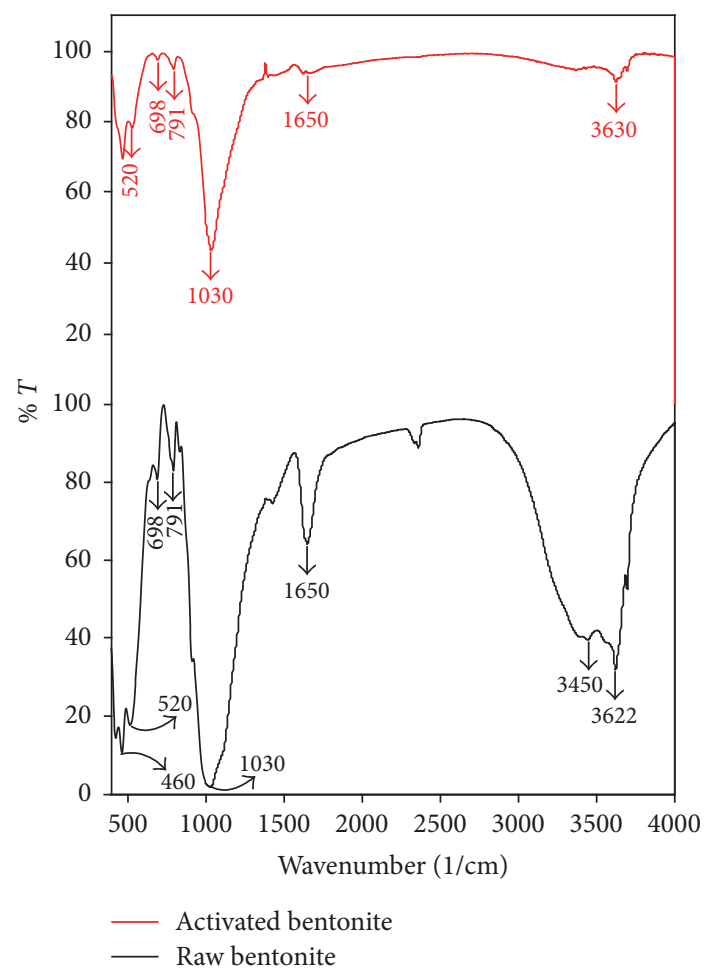

FIGURE 1: FTIR spectra of raw and acid activated Jordanian bentonite.

a band at $3620 \mathrm{~cm}^{-1}$ representing the stretching vibration of the hydroxyl groups coordinated to octahedral $\mathrm{Al}^{3+}$ cations. Very strong absorption band at $1030 \mathrm{~cm}^{-1}$ is recognized for stretching vibration $\mathrm{Si}-\mathrm{O}$ bands, which is strong evidence for a silicate structure. The bands are at 520 for Si-O-Al (octahedral) and $460 \mathrm{~cm}^{-1}$ for Si-O-Si bending vibrations. The spectrum also contains a band at 791 and $698 \mathrm{~cm}^{-1}$ which is attributed to cristobalite and quartz, respectively [40, 41].

During the acid activation of bentonite, a decrease in the intensity of stretching and bending bands (a characteristic of octahedral sheet for Al-Al-OH) is observed at $1650 \mathrm{~cm}^{-1}$, which reflects the leaching of octahedral cations, such as $\mathrm{Al}^{3+}$ and $\mathrm{Mg}^{2+}$, from the bentonite structure, thus indicating the destruction of the octahedral layer. Moreover, a sharp decrease in the absorption band attributed to the $\mathrm{OH}$ vibration at $3630 \mathrm{~cm}^{-1}$ is due to the removal of the octahedral cations, thus causing the loss of water and hydroxyl groups coordinated to them [22]. This might indicate the presence of free $\mathrm{OH}$ sites on activated bentonite. The most significant change was a decrease in the intensity of the band at $1030 \mathrm{~cm}^{-1}$, due to the formation of three-dimensional networks of amorphous silica, which may expose more adsorption sites. In addition, the distortion in the intensity of the band at $791 \mathrm{~cm}^{-1}$ indicates there is an amount of amorphous silica, as acid dissolution progresses to the deterioration of tetrahedral layer. This treatment leaves material rich in amorphous silica [42]. The bands at 520,698, and $791 \mathrm{~cm}^{-1}$ associated with $\mathrm{Si}-\mathrm{O}-\mathrm{Al}$ vibration decreased after the acid treatment of the bentonite sample and this result 


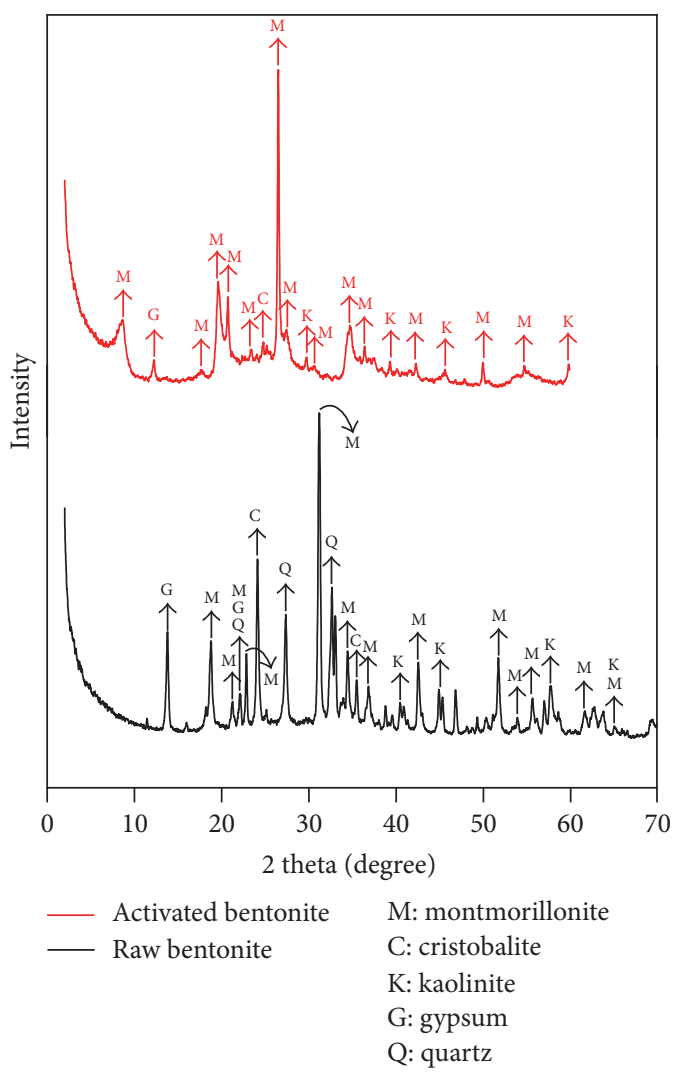

FIGURE 2: X-ray diffractograms of raw and acid activated Jordanian bentonite.

suggests the partial depletion of $\mathrm{Al}, \mathrm{Mg}$, and $\mathrm{Fe}$ from the clay structure, in accordance with the changes in chemical composition [43]. Furthermore, acid activation caused the disappearance of the stretching bands at 3450, 2360, and $1430 \mathrm{~cm}^{-1}$ assigned to the $\mathrm{H}-\mathrm{O}-\mathrm{H}$ stretching, which indicates that modification was affected in this position. During the acid activation process, the protons from the acid medium penetrated into the bentonite structure and attacked the $\mathrm{OH}$ groups, thereby causing alterations in the adsorption bands attributed to the $\mathrm{OH}$ vibration and octahedral cations, as mentioned earlier [44]. Finally, following the activation process, most band positions did not change, thus suggesting that the basic bentonite structure did not collapse.

3.1.2. X-Ray Diffractograms. XRD analysis of raw bentonite shows the presence of montmorillonite as the major component. Gypsum, cristobalite, and quartz are also present [45]. Activation of bentonite by hydrochloric acid clearly causes a decrease in peak intensity. This mostly occurs for the montmorillonite, which means a reduction in its content. Also, the quartz content, which is seen as an impurity, disappears after activation. The reduction in intensity and the increase in the width of peak at $24.1 \AA$ indicate that the crystallinity of the bentonite is considerably affected by acid activation and the bentonite crystalline structure is decomposing, which means that the activation process is accompanied by the appearance of an amorphous phase, as shown in Figure 2.

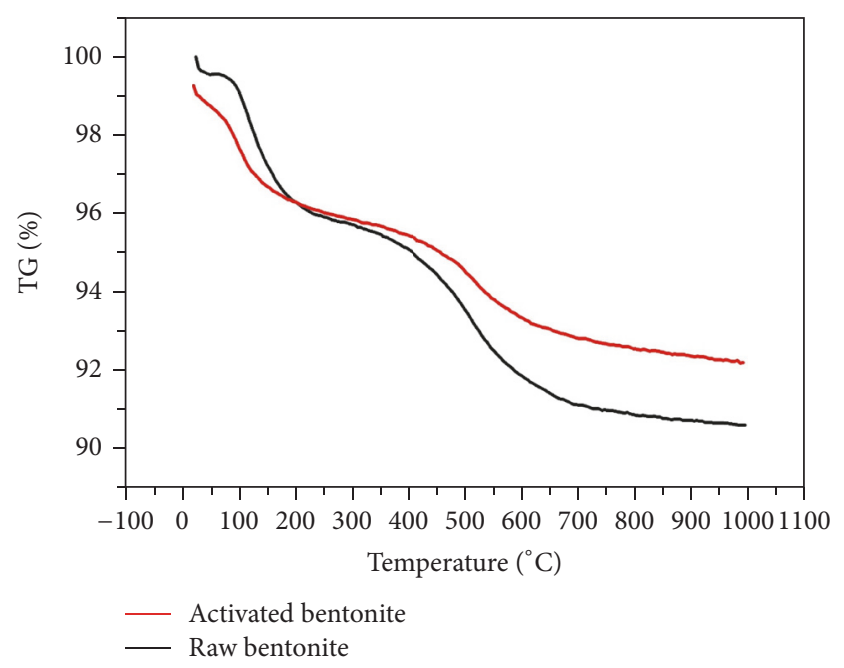

FIGURE 3: TGA curves of raw and acid activated Jordanian bentonite.

Similar results have already been described in the literature [44]. Moreover, X-ray results of activated bentonite show that there is a change in the position of a few peaks (e.g., 31.2 to $26.5 \AA$ ), which is related to the change of distance between layers. This is an indication of dissolution of the tetrahedral and octahedral sheets and subsequent release of the structural cations; that is, these cations have been eliminated from the octahedral positions thereby leaving some vacancies. Notice that the rates of depletion of the octahedral cations follow the order $\mathrm{Mg}^{2+}>\mathrm{Fe}^{2+}>\mathrm{Fe}^{3+}>\mathrm{Al}^{3+}$. Amorphous $\mathrm{SiO}_{2}$ appears on the edges and flats of flakes of bentonite are an indication of a grown delamination of the original particles [46].

Distinctly, XRD analysis provides good evidence that the adsorptive power of acid activated bentonite has increased.

3.1.3. Thermogravimetric Analysis (TGA). Temperature treatment of raw and activated bentonite was carried out in the region of $100-1000^{\circ} \mathrm{C}$ in air for $90 \mathrm{~min}$. Figure 3 shows that the samples present double endothermic changes between 30 and $200^{\circ} \mathrm{C}$, related to the presence of free and absorbed water and the dehydration process. The presence of double endothermic changes up to $200^{\circ} \mathrm{C}$ is related to the presence of coordinated water to $\mathrm{Ca}^{2+}$ and $\mathrm{Mg}^{2+}$ [47]. A significant weight loss is observed in the raw bentonite in the range between 325 and $720^{\circ} \mathrm{C}$, with a maximum at $350^{\circ} \mathrm{C}$, which can be attributed to the dehydroxylation of the clay minerals present in the clay, whereas, for the activated bentonite, the weight loss has taken place in a smaller range, from 410 to $645^{\circ} \mathrm{C}$. This means a constant weight of bentonite is achieved and there is no more decomposition of clay minerals, even if a further increase in temperature is performed. This gives an indication that the activated bentonite shows more thermal stability than the raw bentonite, which enhances its properties towards using it in different applications. Furthermore, the TGA result is in clear agreement with the FTIR and XRD studies, which indicate consecutive changes of the bentonite sheet upon acid activation. 


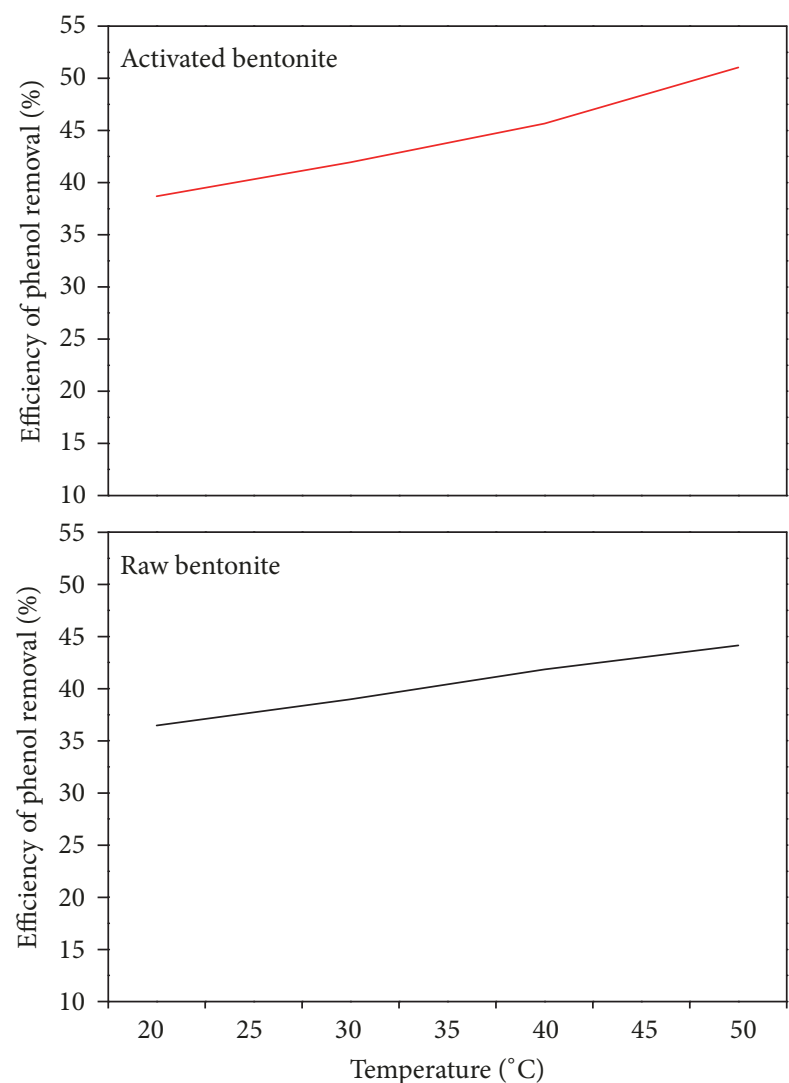

Figure 4: Comparison of percentage removals of total phenolic compounds by raw and activated bentonite. Operation conditions: $10 \mathrm{~mL}$ of OMWW, mass of activated bentonite $=1.0 \mathrm{~g}$, and contact time $=3 \mathrm{hrs}$.

3.1.4. Determination of BET Surface Area. The surface area of bentonite shows a significant increase with activation by acid. Measured values are 66.2 and $287.8 \mathrm{~m}^{2} \mathrm{~g}^{-1}$ for raw and activated bentonite, respectively. Since this increase is a result of removing impurities, replacement of exchangeable cations, such as $\mathrm{K}^{+}, \mathrm{Na}^{+}$, and $\mathrm{Ca}^{2+}$, with $\mathrm{H}^{+}$ions, and leaching out $\mathrm{Al}^{3+}, \mathrm{Fe}^{3+}$, and $\mathrm{Mg}^{2+}$ from the octahedral and tetrahedral sheets, which expose the edges of the plates [48], now, the surface area becomes very high, and this shows the generation of microporosity during the activation, thus providing a relatively suitable surface for phenolic compounds and heavy metal ions adsorption. On the other hand, the presence of a metal oxides component in the clay mineral decreases the Bronsted surface acidity and thus affects the adsorption capacity and selectivity. Therefore, the bentonite clay was pretreated with acids to improve the surface acidity and acidic sites of the clay. It possesses strong Lewis acid sites, which makes it suitable for heavy metal ions adsorption and the removal of phenolic compounds.

3.1.5. Measurement of Point of Zero Charge (PZC). The $\mathrm{pH}$ of the solution has an important effect on the adsorption process, since the $\mathrm{pH}$ of the solution controls the magnitude of electrostatic charges and the degree of ionization of the adsorbate [49]. Therefore, the PZC of the adsorbent should be measured, and it was 3.2 and 2.3 for raw and activated bentonite, respectively. It can be clearly reasoned that the value and signs of the surface potential of a specific adsorbent are directly determined by the nature of specifically adsorbed ions. As the solution $\mathrm{pH}$ decreases, more protons are expected to adsorb to the surface of the bentonite, which results in an increase of surface potential. The measured PZC values offer a good indication for activated bentonite by $\mathrm{HCl}$. Indeed, the surface area measurement and PZC studies are consistent with previous results, thus supporting the consideration that the bentonite is activated by acid.

3.1.6. Characteristics of OMWW. The OMWW samples were analyzed prior to treatment for different physicochemical properties and the results of the analysis are shown in Table 1. It is worth noting here that the parameter values are in good agreement with those reported in the literature. Furthermore, a simple comparison was made between the raw and activated adsorbent, in order to study their effect on OMWW properties. As seen, there is an increase in the percentage removal when activated bentonite was used, which means that this simple treatment of bentonite can lead to a good result, in regard to its adsorption capacity, and therefore, it can reduce the concentration of different present parameters, thus making OMWW eco-friendly.

\subsection{Adsorption Experiments}

3.2.1. Total Phenolic Compounds Removal. Acid activated bentonite for the total removal of phenolic compounds was examined using a batch technique; a series of experiments were performed at $\mathrm{pH} 6(\mathrm{pH} 6$ value was less than the $\mathrm{pKa}$ of phenol ( $\approx 9.92)$ ).

However, when $\mathrm{pH}$ value is greater than the $\mathrm{pKa}$ of phenol, phenol would dissociate to negatively charged species, such as $\mathrm{C}_{6} \mathrm{H}_{5} \mathrm{O}^{-}$[50], and then there are more electrostatic repulsions between the dissociated form of the phenol and the activated bentonite and so a decrease in the adsorbed amount of phenol. While $\mathrm{pH}$ value is 6 , activated bentonite has more removal efficiency, as its particles have active sites with negative charges at relatively acidic $\mathrm{pH}$ and phenol is undissociated. Hence, the dispersion interaction predominated. Furthermore, the higher concentration of $\mathrm{H}^{+}$ions within a low solution $\mathrm{pH}$ can neutralize those negative sites and reduce the hindrance to diffusion of phenol ions from the aqueous solution and consequently increase the chances of their adsorption. However, at the high solution $\mathrm{pH}, \mathrm{OH}-$ concentration ions dominate, which can, in turn, increase the hindrance to the diffusion of phenol ions and thus reduce the chances of their adsorption; Figure 4 shows these results. A similar trend was also observed in the study conducted by Alkaram et al. [51] for phenol removal from aqueous solutions using surfactant-modified bentonite and kaolinite.

Effect of Adsorbent Dose on Adsorption of Total Phenolic Compounds. The influence of adsorbent dose on the adsorption of total phenolic compounds from the OMWW is shown in Figure 5. An increase in phenolic compounds removal with 

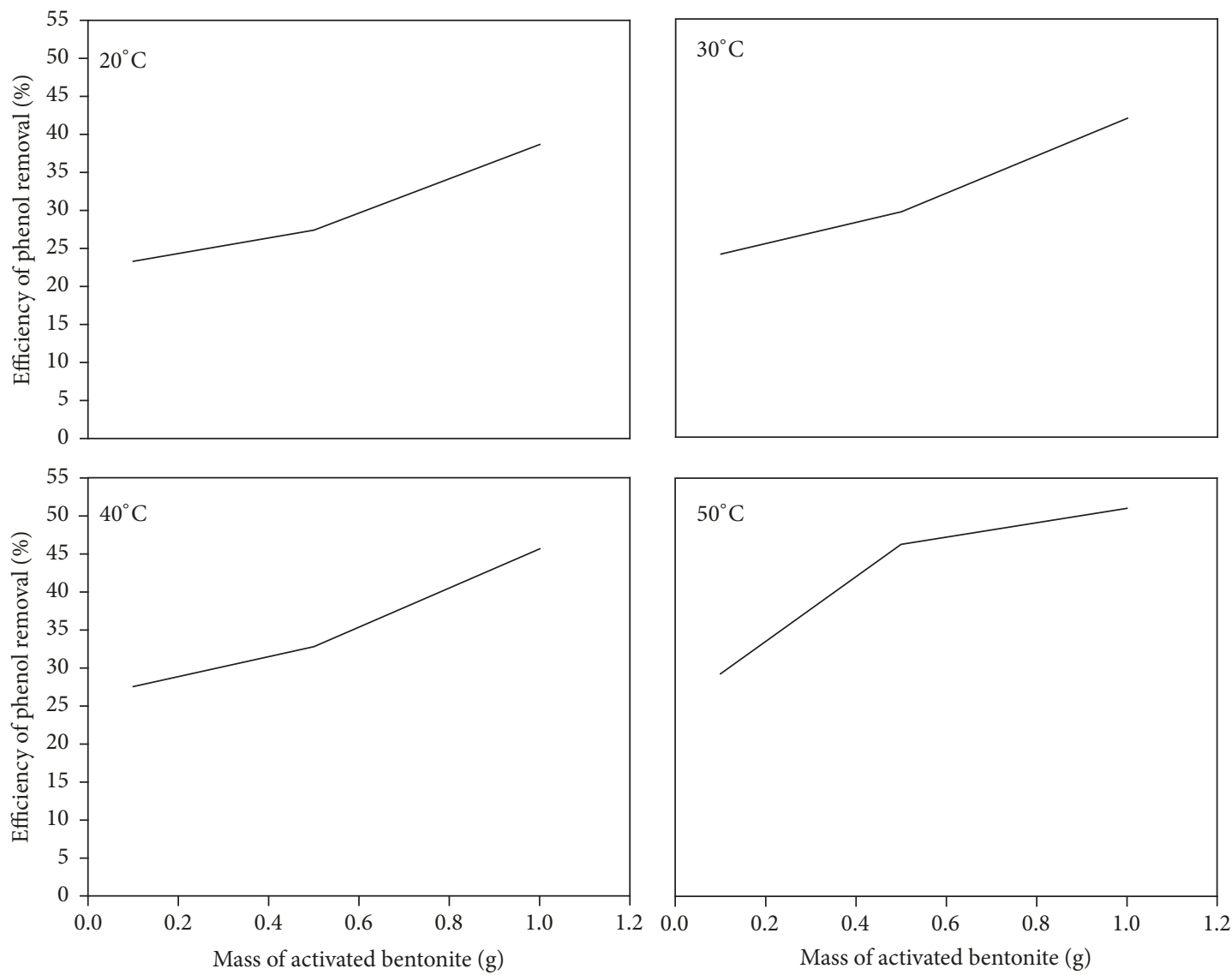

FIGURE 5: Effect of mass acid activated bentonite on percentage removal of total phenolic compounds.

TABLE 1: Main characteristics of OMWW sample, untreated and treated with raw and activated bentonite.

\begin{tabular}{|c|c|c|c|c|c|c|c|}
\hline Parameters & $\begin{array}{l}\text { Untreated } \\
\text { OMWW }\end{array}$ & $\begin{array}{c}\text { Literature } \\
\text { ranges values }\end{array}$ & Reference & $\begin{array}{c}\text { Treated OMWW } \\
\text { with raw bentonite }\end{array}$ & $\begin{array}{c}\text { Treated OMWW } \\
\text { with activated } \\
\text { bentonite }\end{array}$ & $\begin{array}{c}\text { \% removal } \\
\text { using raw } \\
\text { bentonite }\end{array}$ & $\begin{array}{c}\% \text { removal using } \\
\text { activated } \\
\text { bentonite }\end{array}$ \\
\hline $\mathrm{pH}$ & 4.63 & $4.9-6.50$ & {$[26]$} & 5.74 & 5.08 & --- & --- \\
\hline Conductivity, $\mathrm{ms} / \mathrm{cm}$ & 19.89 & $13-50$ & {$[27,28]$} & 19.4 & 16.9 & ---- & ---- \\
\hline Sodium $\left(\mathrm{Na}^{+}\right), \mathrm{mg} \mathrm{L}^{-1}$ & 297.9 & $200-570$ & {$[29,30]$} & 186.4 & 114.6 & 37.4 & 61.5 \\
\hline $\begin{array}{l}\text { Potassium }\left(\mathrm{K}^{+}\right) \\
\mathrm{mg} \mathrm{L}^{-1}\end{array}$ & 6366.3 & $639-10800$ & {$[31]$} & 4075.1 & 2215.7 & 35.9 & 65.2 \\
\hline $\begin{array}{l}\text { Total phenolic } \\
\text { content, g GAE/L }\end{array}$ & 1.34 & $0.26-10.7$ & {$[31,32]$} & 0.85 & 0.42 & 36.6 & 65.7 \\
\hline $\begin{array}{l}\text { Alkalinity }\left(\mathrm{CaCO}_{3}\right) \\
\mathrm{mg} \mathrm{L}^{-1}\end{array}$ & 2000 & $3150-9070$ & {$[33]$} & 1500 & 500 & 25.0 & 75.0 \\
\hline Total chlorine, $\mathrm{mg} \mathrm{L}^{-1}$ & 20 & $33.3-142.7$ & {$[34]$} & 15 & 7 & 25.0 & 65.0 \\
\hline $\begin{array}{l}\text { Phosphate }\left(\mathrm{PO}_{4}^{3-}\right) \\
\mathrm{mg} \mathrm{L}^{-1}\end{array}$ & 4120 & $31.8-1820$ & [35] & 460 & 155 & 88.8 & 96.2 \\
\hline $\begin{array}{l}\text { Nitrate }\left(\mathrm{NO}_{3}{ }^{-}-\mathrm{N}\right) \text {, } \\
\mathrm{mg} \mathrm{L}^{-1}\end{array}$ & 360 & $350-390$ & {$[36]$} & 230 & 28 & 36.1 & 92.2 \\
\hline $\mathrm{COD}, \mathrm{mg} \mathrm{L}^{-1}$ & 12000 & $1900-220000$ & {$[37,38]$} & 7030 & 2295 & 41.4 & 80.9 \\
\hline $\mathrm{DO}, \mathrm{mg} \mathrm{L}^{-1}$ & 600 & n.d. & ---- & 297 & 274 & 50.5 & 54.3 \\
\hline TDS, $\mathrm{mg} \mathrm{L}^{-1}$ & 34700 & $5900-103200$ & {$[37,39]$} & 13140 & 11010 & 62.1 & 71.2 \\
\hline ORP, mv & 259800 & n.d. & ---- & 73300 & 61100 & 71.8 & 76.5 \\
\hline Salt, $\mathrm{mg} \mathrm{L}^{-1}$ & 26700 & $11900-32000$ & {$[33]$} & 9930 & 6010 & 62.8 & 77.5 \\
\hline
\end{tabular}

n.d.: not determined. 


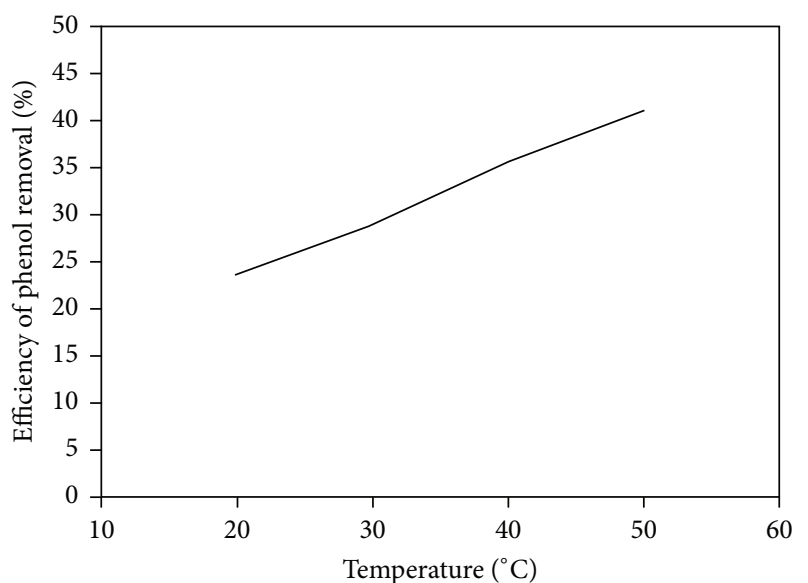

FIGURE 6: Effect of solution temperature on the percentage removal of total phenolic compounds. Operation conditions: $10 \mathrm{~mL}$ of OMWW, mass of activated bentonite $=1.0 \mathrm{~g}$, and contact time $=$ 3 hrs.

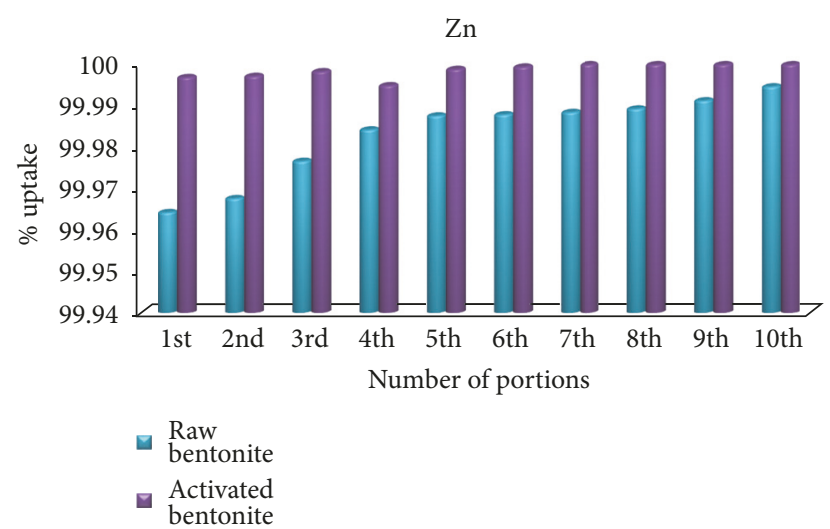

FIgURE 7: Percentage uptake of $\mathrm{Zn}(\mathrm{II})$ by raw and acid activated bentonite using column technique.

an increase in adsorbent dose was recorded. This increase may be due to the higher adsorbent dose providing more active adsorption sites or surface areas, so more phenol molecules have the chance to attach to these adsorbent particles, which results in an increase of adsorption capacity of the activated bentonite.

Furthermore, the optimum adsorbent concentration needed for the maximum removal of total phenolic compounds is $1 \mathrm{~g}$ of bentonite $/ 0.01 \mathrm{~L}$ of OMWW.

Effect of Temperature on Adsorption of Total Phenolic Compounds. Studies have shown that temperature also influences the overall adsorption process. As shown in Figure 6, adsorption efficiency is directly related to temperature. This is because the dissolution rate of cations $\left(\mathrm{K}^{+}, \mathrm{Na}^{+}\right.$, and $\left.\mathrm{Ca}^{2+}\right)$ in the acid medium increases, as the leaching temperature increases up to the maximum temperature used in this study. The increase in the removal rate of the cation could be a result of high kinetic energy in the system, which speeds up the rate of reaction on the surface of the bentonite. Therefore,

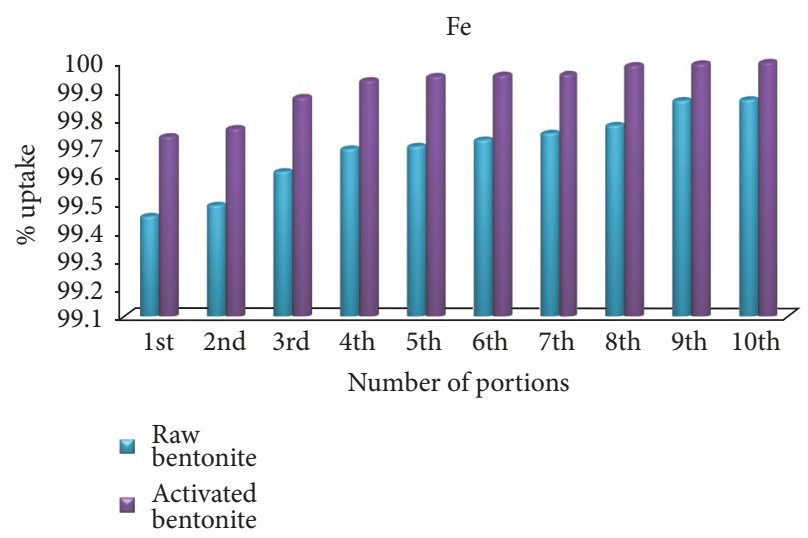

FIgURE 8: Percentage uptake of Fe(II) by raw and acid activated bentonite using column technique.

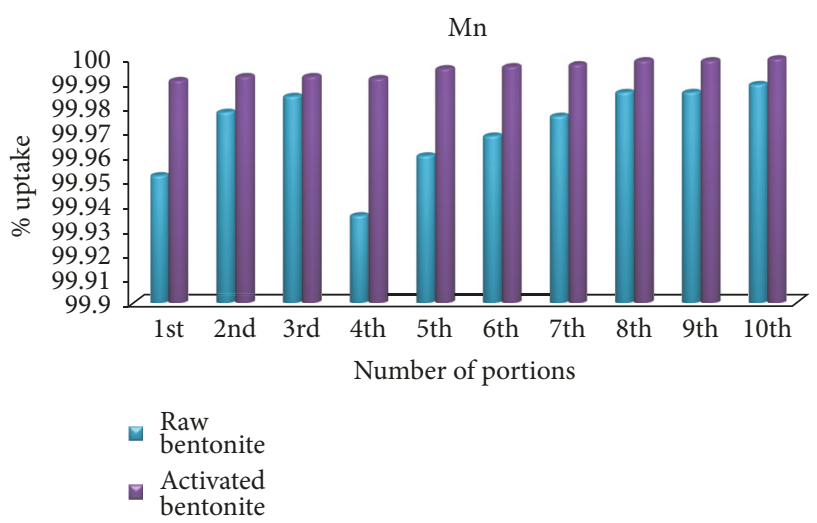

FIGURE 9: Percentage uptake of $\mathrm{Mn}$ (II) by raw and acid activated bentonite using column technique.

the higher temperature generates a greater driving force for phenolic compounds to be fixed on the adsorbent. The same trend has been reported by the others [52].

Comparisons between raw and activated bentonite for the total removal of phenolic compounds have been examined in other studies, where it was observed that acid activation of bentonite enhanced its adsorption capacity. Figure 6 supports this observation.

Up to now, OMWW is discharged directly into sewer systems, valleys, and uncontrolled ponds, even though such discarding methods are forbidden in many Mediterranean countries. This is due to the current absence of applicable treating technologies for OMWW. Therefore, we introduce this desirable, low-cost method as an effective treatment of OMWW and other contaminated aqueous solutions.

3.2.2. Heavy Metal Ions Removal. In order to compare the adsorption potentials of raw and activated bentonite, $\mathrm{pH} 6$ was chosen and utilized as optimum adsorption of metal ions from OMWW using a column technique. The significant adsorption occurring at $\mathrm{pH}$ values is greater than the PZC, at which the surface of activated bentonite is negative. The adsorption process increased with an increase in $\mathrm{pH}$ up to 6 , due to a decrease in competition between protons and 
metal ions leading to a higher uptake (Akpomie and Dawodu 2016). In addition, avoiding high $\mathrm{pH}$ values (>6), metal hydroxide may be precipitated in solution [53]. Also, $1 \mathrm{~g}$ of bentonite/0.1 L of OMWW is considered as the optimum adsorbent concentration needed for the maximum removal of all heavy metal ions. Figures 7, 8, and 9 show a comparison of the percentage uptakes of heavy metal ions by raw and activated bentonite.

It can be clearly observed that activated bentonite can completely remove all heavy metal ions from OMWW, regardless of their initial concentrations.

\section{Conclusion}

OMWW is produced in Jordan and Mediterranean regions in huge amounts and results in heavily polluted waste water that causes negative environmental impacts. Untreated OMWW is characterized by a high content of phenolic compounds, some heavy metals, and other salts.

Bentonite has been successfully activated using hydrochloric acid, as shown by FTIR, XRD, and TGA studies, in addition to an increase in its surface area. Acid activated bentonite shows a great potential for the removal of heavy metal ions and phenolic compounds pollutants. Results show that percentage uptakes exceed $99 \%$ for $\mathrm{Zn}, \mathrm{Fe}$, and $\mathrm{Mn}$ ions. According to phenolic compounds, adsorption efficiency is strongly affected by parameters, such as $\mathrm{pH}$ of the solution, temperature, and adsorbent dosage. The efficiency rises with an increase in the temperature of solution and the adsorbent dose.

This method is simple, economical, green, nontoxic, and fast, Therefore, we recommend its use for OMWW treatment in developing countries.

\section{Conflicts of Interest}

The author declares that there are no conflicts of interest regarding the publication of this manuscript.

\section{Acknowledgments}

The author acknowledges the Support to Research and Technological Development \& Innovation Initiatives and Strategies in Jordan (SRTD II), the European Union Funded Project, Budget Line BGUE-2011-19.080101-CI-DEVCO, reference SRTD/2014/GRT/AR/2321, for funding the project, in addition to Jerash University.

\section{References}

[1] E. Frankel, A. Bakhouche, J. Lozano-Sánchez, A. Segura-Carretero, and A. Fernández-Gutiérrez, "Literature review on production process to obtain extra virgin olive oil enriched in bioactive compounds. Potential use of byproducts as alternative sources of polyphenols," Journal of Agricultural and Food Chemistry, vol. 61, no. 22, pp. 5179-5188, 2013.

[2] P. Alicanoğlu, C. Ulusoy, and D. Sponza, "Effect of graphene$\mathrm{TiO}_{2}$ on the photodegradation of olive mill effluent and recovery of graphene-TiO, , Sigma Journal of Engineering and Natural Sciences, vol. 8, no. 3, pp. 227-234, 2017.
[3] I. Leouifoudi, H. Harnafi, and A. Zyad, "Olive Mill Waste Extracts: Polyphenols Content, Antioxidant, and Antimicrobial Activities," Advances in Pharmacological Sciences, vol. 2015, Article ID 714138, 11 pages, 2015.

[4] T. Campani, I. Caliani, C. Pozzuoli, M. Romi, M. C. Fossi, and S. Casini, "Assessment of toxicological effects of raw and bioremediated olive mill waste in the earthworm Eisenia fetida: A biomarker approach for sustainable agriculture," Applied Soil Ecology, vol. 119, pp. 18-25, 2017.

[5] R. Dakhli, "Study of the effect of olive mill waste water sludge on soil chemical properties and on autochthonous pear millet ecotype (Pennisetum Glaucum (L) R.BR) behavior in southern Tunisian," International Journal of Environmental Quality, vol. 23, pp. 1-18, 2017.

[6] N. Abdel-Raouf, A. A. Al-Homaidan, and I. B. M. Ibraheem, "Microalgae and wastewater treatment," Saudi Journal of Biological Sciences, vol. 19, no. 3, pp. 257-275, 2012.

[7] E. E. Okorie, S. E. Obalum, and L. Singh, "The potential of fermented cottonseed oil-mill effluent as inexpensive biofertilizers and its agronomic evaluation on medium-textured tropical soil," International Journal of Recycling of Organic Waste in Agriculture, vol. 6, no. 2, pp. 117-123, 2017.

[8] C. Gamba, C. Piovanelli, R. Papini, B. Pezzarossa, L. Ceccarini, and E. Bonari, "Soil microbial characteristics and mineral nitrogen availability as affected by olive oil waste water applied to cultivated soil," Communications in Soil Science and Plant Analysis, vol. 36, no. 7-8, pp. 937-950, 2005.

[9] P. Cañizares, J. Lobato, R. Paz, M. A. Rodrigo, and C. Sáez, "Advanced oxidation processes for the treatment of olive-oil mills wastewater," Chemosphere, vol. 67, no. 4, pp. 832-838, 2007.

[10] A. S. Stasinakis, "Use of selected advanced oxidation processes (AOPs) for wastewater treatment: a mini review," Global NEST Journal, vol. 10, no. 3, pp. 376-385, 2008.

[11] M. D. Víctor-Ortega, J. M. Ochando-Pulido, G. Hodaifa, and A. Martinez-Ferez, "Final purification of synthetic olive oil mill wastewater treated by chemical oxidation using ion exchange: Study of operating parameters," Chemical Engineering and Processing: Process Intensification, vol. 85, pp. 241-247, 2014.

[12] J. M. Ochando-Pulido and A. Martinez-Ferez, "On the recent use of membrane technology for olive mill wastewater purification," Membranes, vol. 5, no. 4, pp. 513-531, 2015.

[13] M. S. Lucas and J. A. Peres, “Treatment of olive mill wastewater by a combined process: Fenton's reagent and chemical coagulation," Journal of Environmental Science and Health, Part A: Toxic/Hazardous Substances and Environmental Engineering, vol. 44, no. 2, pp. 198-205, 2009.

[14] H. Inan, A. Dimoglo, H. Şimşek, and M. Karpuzcu, "Olive oil mill wastewater treatment by means of electro-coagulation," Separation and Purification Technology, vol. 36, no. 1, pp. 23-31, 2004.

[15] P. Aytar, S. Gedikli, M. Sam, B. Farizoğlu, and A. Çabuk, "Sequential treatment of olive oil mill wastewater with adsorption and biological and photo-Fenton oxidation," Environmental Science and Pollution Research, vol. 20, no. 5, pp. 3060-3067, 2013.

[16] A. Yangui, M. Abderrabba, and A. Sayari, "Amine-modified mesoporous silica for quantitative adsorption and release of hydroxytyrosol and other phenolic compounds from olive mill wastewater," Journal of the Taiwan Institute of Chemical Engineers, vol. 70, pp. 111-118, 2017.

[17] A. Yangui, J. R. Njimou, A. Cicci, M. Bravi, M. Abderrabba, and A. Chianese, "Competitive adsorption, selectivity and 
separation of valuable hydroxytyrosol and toxic phenol from olive mill wastewater," Journal of Environmental Chemical Engineering (JECE), vol. 5, no. 4, pp. 3581-3589, 2017.

[18] J. M. Ochando-Pulido, R. González-Hernández, and A. Martinez-Ferez, "On the effect of the operating parameters for two-phase olive-oil washing wastewater combined phenolic compounds recovery and reclamation by novel ion exchange resins," Separation and Purification Technology, vol. 195, pp. 5059, 2018.

[19] D. Pinelli, A. E. Molina Bacca, A. Kaushik et al., "Batch and Continuous Flow Adsorption of Phenolic Compounds from Olive Mill Wastewater: A Comparison between Nonionic and Ion Exchange Resins," International Journal of Chemical Engineering, vol. 2016, Article ID 9349627, 13 pages, 2016.

[20] A. A. Adeyemo, I. O. Adeoye, and O. S. Bello, "Adsorption of dyes using different types of clay: a review," Applied Water Science, vol. 7, pp. 543-568, 2017.

[21] R. O. Ajemba, "Modification of Ntezi bentonite structure by hydrochloric acid: Process kinetics and structural properties of the modified samples," Pakistan Journal of Scientific and Industrial Research Series A: Physical Sciences, vol. 57, no. 1, pp. 1-9, 2014.

[22] R. Ajemba, "Structural alteration of bentonite from nkaliki by acid treatment: studies of the kinetics and properties of the modified samples," nternational Journal of Advances in Engineering \& Technology, vol. 7, no. 1, pp. 379-392, 2014.

[23] M. Aliu, L. Pula-Beqiri, S. Kadriu et al., "Research of the Chemical Composition and Ion Exchange Properties of Karaçeva Bentonite," Journal of International Environmental Application \& Science, vol. 11, no. 4, pp. 409-413, 2016.

[24] F. Kooli, Y. Liu, R. Al-Faze, and A. Al Suhaimi, "Effect of acid activation of Saudi local clay mineral on removal properties of basic blue 41 from an aqueous solution," Applied Clay Science, vol. 116-117, pp. 23-30, 2015.

[25] I. Leouifoudi, A. Zyad, A. Amechrouq, M. A. Oukerrou, H. A. Mouse, and M. Mbarki, "Identification and characterisation of phenolic compounds extracted from Moroccan olive mill wastewater," Food Science and Technology, vol. 34, no. 2, pp. 249257, 2014.

[26] P. Galiatsatou, M. Metaxas, D. Arapoglou, and V. KasselouriRigopoulou, "Treatment of olive mill waste water with activated carbons from agricultural by-products," Waste Management, vol. 22, no. 7, pp. 803-812, 2002.

[27] A. Ben Sassi, A. Boularbah, A. Jaouad, G. Walker, and A. Boussaid, "A comparison of Olive oil Mill Wastewaters (OMW) from three different processes in Morocco," Process Biochemistry, vol. 41, no. 1, pp. 74-78, 2006.

[28] M. G. Di Serio, B. Lanza, M. R. Mucciarella et al., "Effects of olive mill wastewater spreading on the physico-chemical and microbiological characteristics of soil," International Biodeterioration \& Biodegradation, vol. 62, no. 4, pp. 403-407, 2008.

[29] C. I. Piperidou, C. I. Chaidou, C. D. Stalikas, K. Soulti, G. A. Pilidis, and C. Balis, "Bioremediation of olive oil mill wastewater: Chemical alterations induced by Azotobacter vinelandii," Journal of Agricultural and Food Chemistry, vol. 48, no. 5, pp. 1941-1948, 2000.

[30] E. Eroğlu, I. Eroğlu, U. Gündüz, and M. Yücel, "Effect of clay pretreatment on photofermentative hydrogen production from olive mill wastewater," Bioresource Technology, vol. 99, no. 15, pp. 6799-6808, 2008.

[31] F. Hanafi, N. Sadif, O. Assobhei, and M. Mountadar, "Traitement des margines par électrocoagulation avec des électrodes plates en aluminium," Journal of Water Science, vol. 22, no. 4, pp. 473485, 2009.

[32] A. G. Vlyssides, M. Loizides, and P. K. Karlis, "Integrated strategic approach for reusing olive oil extraction by-products," Journal of Cleaner Production, vol. 12, no. 6, pp. 603-611, 2004.

[33] M. Mouncif, S. Tamoh, M. Faid, and A. Achkari-Begdouri, "A study of chemical and microbiological characteristics of olive mill waste water in Morocco," Grasas y Aceites, vol. 44, no. 6, pp. 335-338, 1993.

[34] D. Bouknana, B. Hammouti, R. Salghi et al., "Physicochemical characterization of olive oil mill wastewaters in the eastern region of Morocco," Journal of Materials and Environmental Science, vol. 5, no. 4, pp. 1039-1058, 2014.

[35] A. A. Aly, Y. N. Y. Hasan, and A. S. Al-Farraj, "Olive mill wastewater treatment using a simple zeolite-based low-cost method," Journal of Environmental Management, vol. 145, pp. 341-348, 2014.

[36] M. Panizza and G. Cerisola, "Olive mill wastewater treatment by anodic oxidation with parallel plate electrodes," Water Research, vol. 40, no. 6, pp. 1179-1184, 2006.

[37] J. Alba, "Nuevas tecnolog $\varphi$ as para la obtenci $\leq \mathrm{n}$ del aceite de oliva," Fruticultura Profesional (Suplemento), vol. 62, pp. 85-95, 1994.

[38] P. Passarinho, Olive Mill Wastewater detoxification [Ph.D. thesis], Instituto Superior Técnico, Universidade Técnica de Lisboa, Portugal, 2002.

[39] M. Hamdi, "Thermoacidic precipitation of darkly coloured polyphenols of olive mill wastewaters," Environmental Technology (United Kingdom), vol. 14, no. 5, pp. 495-500, 1993.

[40] W. K. Mekhamer, "Energy storage through adsorption and desorption of water vapour in raw Saudi bentonite," Arabian Journal of Chemistry, vol. 9, pp. S264-S268, 2016.

[41] L. Zhirong, M. Azhar Uddin, and S. Zhanxue, "FT-IR and $\mathrm{XRD}$ analysis of natural Na-bentonite and $\mathrm{Cu}(\mathrm{II})$-loaded $\mathrm{Na}-$ bentonite," Spectrochimica Acta Part A: Molecular and Biomolecular Spectroscopy, vol. 79, no. 5, pp. 1013-1016, 2011.

[42] S. Bendou and M. Amrani, "Effect of Hydrochloric Acid on the Structural of Sodic-Bentonite Clay," Journal of Minerals and Materials Characterization and Engineering, vol. 02, no. 05, pp. 404-413, 2014.

[43] F. Ayari, E. Srasra, and M. Trabelsi-Ayadi, "Removal of lead, zinc and nickel using sodium bentonite activated clay," Asian Journal of Chemistry, vol. 19, no. 5, pp. 3325-3339, 2007.

[44] R. Ajemba, "Enhancement of physicochemical properties of nteje clay to increase its bleaching performance using acid activation," International Journal of Engineering Research and Applications (IJERA), vol. 2, no. 4, pp. 281-288, 2012.

[45] H. Yilmaz and U. Köktürk, "Mineralogical and micromorphological characterization of iron impurity in Gedikler Bentonite Mine (Esme/Usak, Turkey)," Asian Journal of Chemistry, vol. 22, no. 4, pp. 3235-3245, 2010.

[46] G. E. Christidis, P. W. Scott, and A. C. Dunham, "Acid activation and bleaching capacity of bentonites from the islands of Milos and Chios, Aegean, Greece," Applied Clay Science, vol. 12, no. 4, pp. 329-347, 1997.

[47] Y. Sarikaya, M. Onal, B. Baran, and T. Alemdaroglu, "The effect of thermal treatment on some of the physicochemical properties of a bentonite," Clays and Clay Minerals, vol. 48, no. 5, pp. 557-562, 2000.

[48] P. Komadel, M. Janek, J. Madejová, A. Weekes, and C. Breen, "Acidity and catalytic activity of mildly acid-treated Mg-rich 
montmorillonite and hectorite," Journal of the Chemical Society, Faraday Transactions, vol. 93, no. 23, pp. 4207-4210, 1997.

[49] O. Abdelwahab and N. K. Amin, "Adsorption of phenol from aqueous solutions by Luffa cylindrica fibers: Kinetics, isotherm and thermodynamic studies," Egyptian Journal of Aquatic Research, vol. 39, no. 4, pp. 215-223, 2013.

[50] M. H. El-Naas, S. Al-Zuhair, and M. A. Alhaija, "Removal of phenol from petroleum refinery wastewater through adsorption on date-pit activated carbon," Chemical Engineering Journal, vol. 162, no. 3, pp. 997-1005, 2010.

[51] U. F. Alkaram, A. A. Mukhlis, and A. H. Al-Dujaili, "The removal of phenol from aqueous solutions by adsorption using surfactant-modified bentonite and kaolinite," Journal of Hazardous Materials, vol. 169, no. 1-3, pp. 324-332, 2009.

[52] P. Numluk and A. Chaisena, "Sulfuric acid and ammonium sulfate leaching of alumina from Lampang clay," E-Journal of Chemistry, vol. 9, no. 3, pp. 1364-1372, 2012.

[53] C.-R. Wang, X. Ren, W.-X. Li, Z.-F. Hou, C. Ke, and Q. Geng, "Adsorption of zinc and copper heavy metal ions from smelting wastewater using modified lava particles," Polish Journal of Environmental Studies, vol. 22, no. 6, pp. 1863-1869, 2013. 

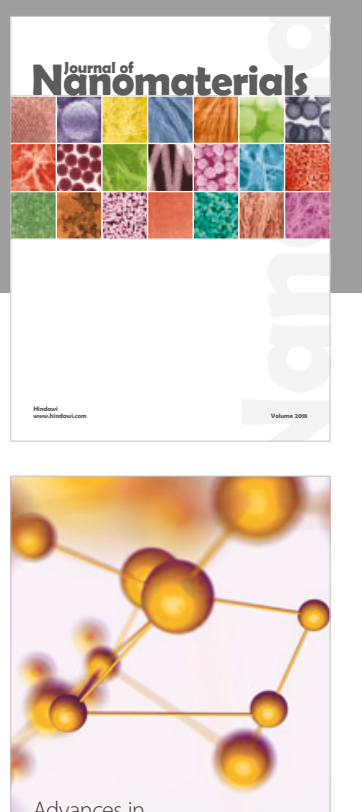

Physical Chemistry
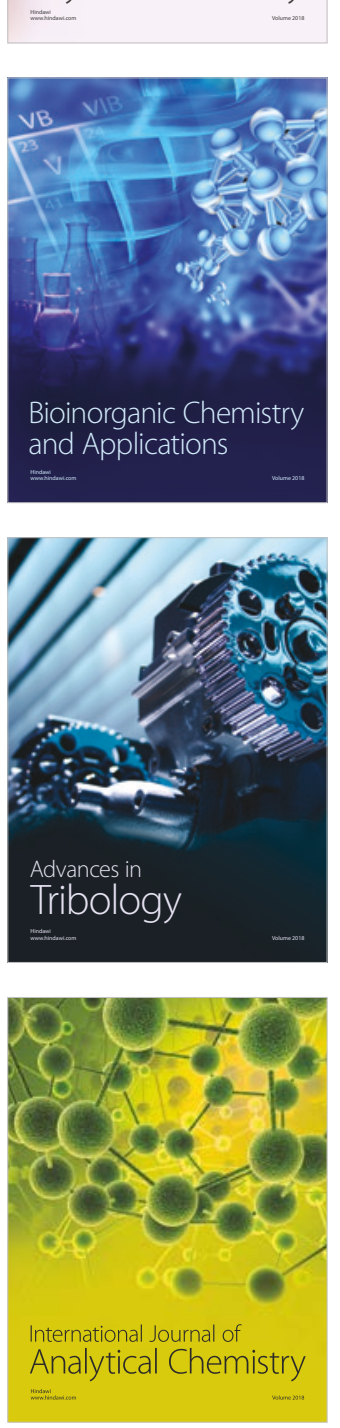

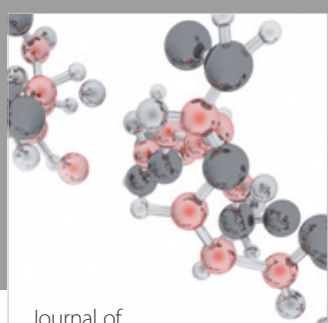

Analytical Methods

in Chemistry

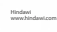

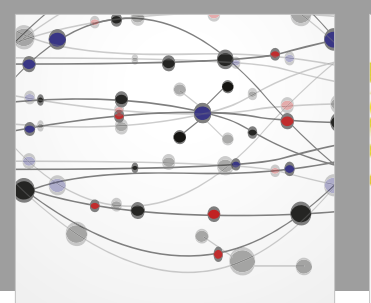

The Scientific World Journal

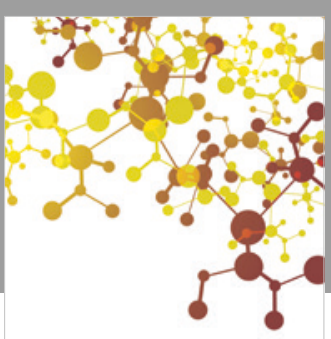

Journal of

Applied Chemistry
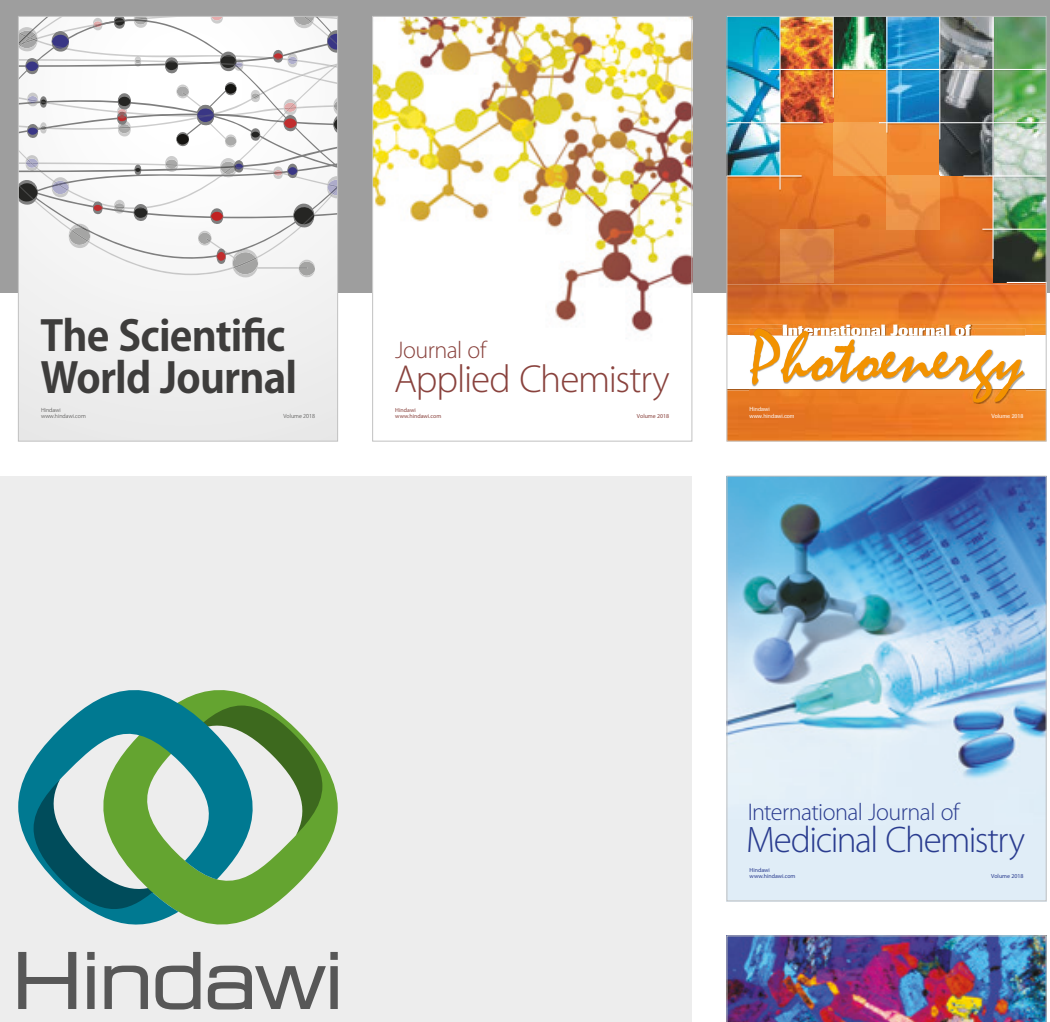

Submit your manuscripts at

www.hindawi.com
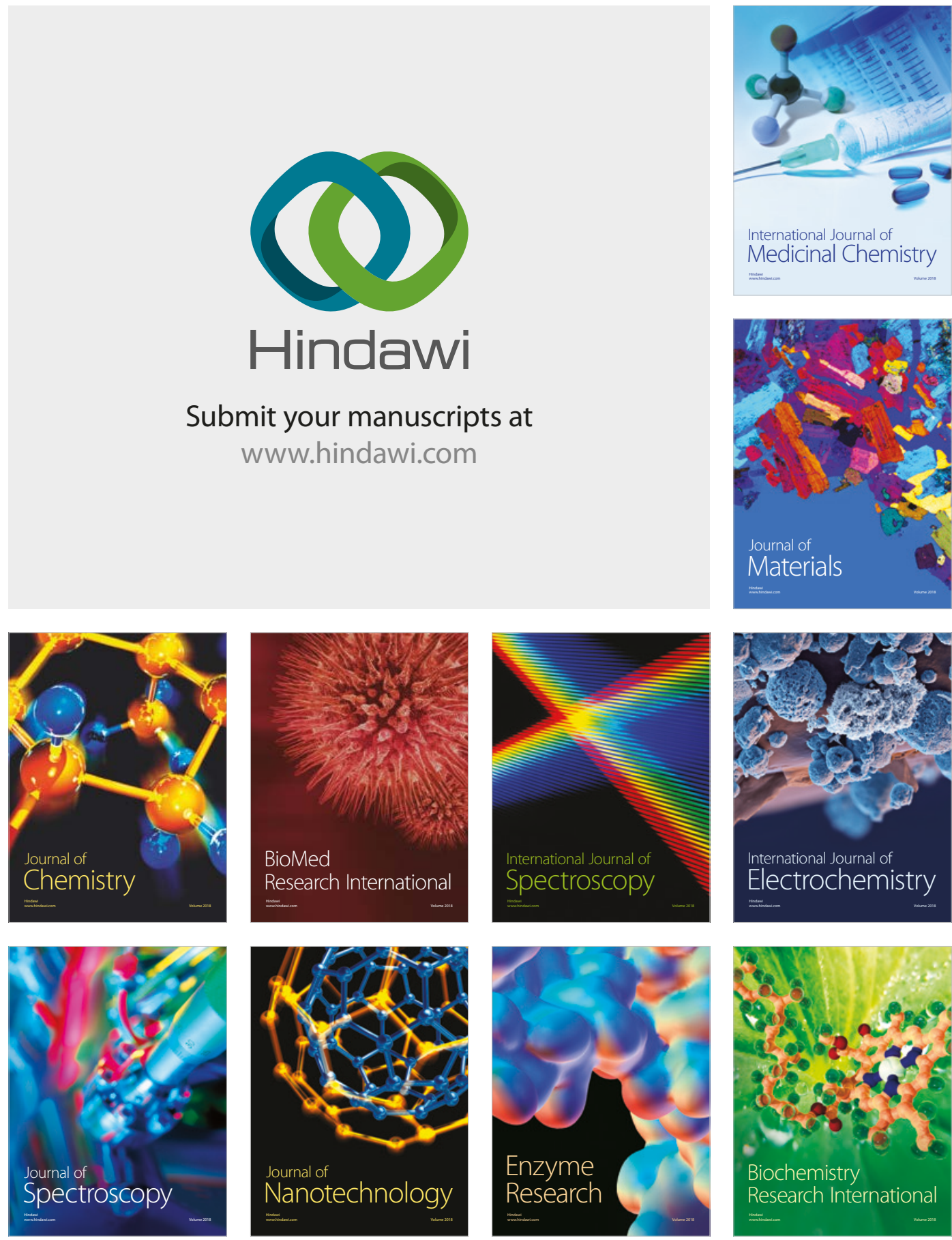
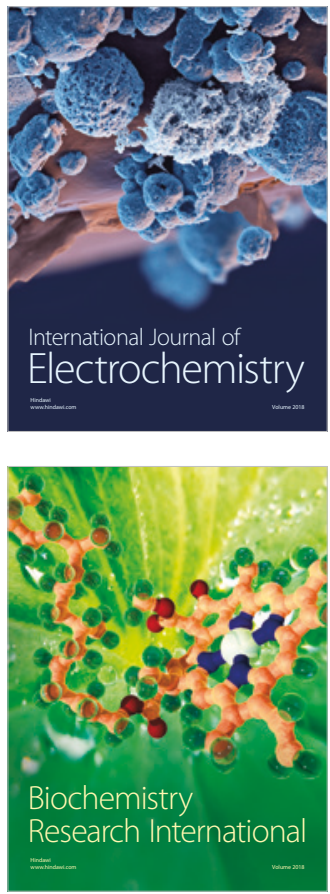